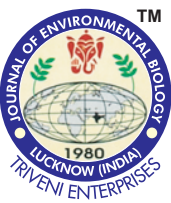

\title{
Production of biodiesel from jojoba oil using ultra sonicator
}

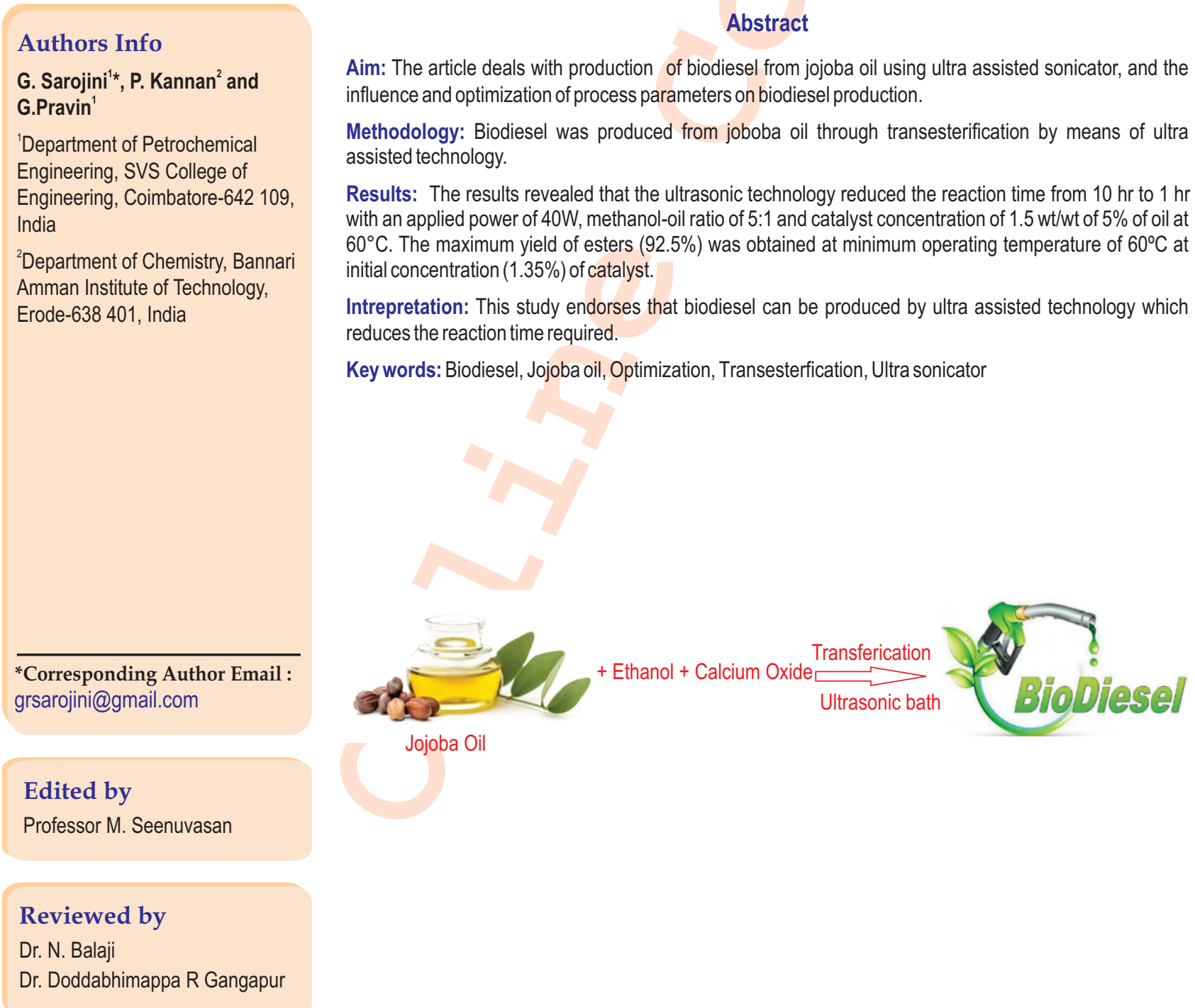

How to cite : Sarojini, G., P. Kannan and G. Pravin: Production of biodiesel from jojoba oil using ultra sonicator. J. Environ. Biol., 40, 802-806 (2019). DOI : http://doi.org/10.22438/jeb/40/4(SI)/JEB_24 


\section{Introduction}

Biodiesel is a fuel consisting of mono-alkyl esters of long chain fatty acids derived from vegetable oil or animal fat. Diesel is an important transportation fuel and crucial factor in the economy of a country. Increasing demand of these fuels due to improvement in modern industrial sectors, huge population and limited supply of fossil fuels stipulates biodiesel as an alternative fuel to meet the requirements. Biodiesel is a promising alternative fuel to conventional diesel and can be used in diesel engines (Dubey et al., 2018). As biofuel produced from renewable source is less toxic, biodegradable and produces lesser emissions compared with petroleum based fuels researchers turned their findings to produce biodiesel from natural resources. Biodiesel is usually produced from oil and fats of plants and animals sources (Yang et al., 2014).Various efforts are being made to synthesis biodiesel from edible and non-edible oil. Conversion of non-edible to biodiesel has attained considerable attention, especially with jojoba oil as it is an ester of long chain alcohol and fatty acid unlike other vegetable oil which are triglycerides (Yan et al., 2014). Jojoba diesel has been synthesized using various organotin and base catalyst with methanol.

Biodiesel is synthesized by transesterification process which involves the reaction of oil with alcohol in the presence of catalyst to convert triglycerides present in oil to methyl or ethyl esters (Yadav et al., 2018). As the reaction is slow acid usually base or enzyme catalyst is mostly employed to increase the reaction rate and yield. Most commonly preferred alcohol is methanol (Verma et al., 2014). The reaction occurs at the interface of two liquids and complete miscible of oil and alcohol is not possible. To promote sufficient interfacial surface area between two immiscible layers, generally mechanical agitation is adopted. Nevertheless, biodiesel is also produced from waste cooking oil (Talebian-Kiakalaieh et al., 2013). Jojoba oil is considered as a non-edible oil and it possess all inherent properties to produce biodiesel. Apart from producing biodiesel it also produces valuable products during transesterification process (Sanchez et al., 2016). Nowadays, ultra-assisted technology has proved to be a promising potential tool for the transesterification reaction as usage of ultrasonic irradiation promotes mass transfer characteristics of the process and enhances complete mixing (Sanchez et al., 2015). Ultrasound when passed into a liquid medium produces mechanical vibration and generates acoustic streaming within the liquid. Furthermore, ultrasonic cavitation is a development of formation, growth and collapse of bubbles in the liquid medium when it is irradiated with ultrasound (Sivaramakrishnan et al., 2018). The collapse of bubbles produce high temperature and pressure spots and shock waves that enhance both mass transfer and heat transfer in liquid medium (El-Boulifi et al., 2015). With the emergence of ultrasound-assisted biodiesel production, various works has been carried out in acid and base-catalysed esterification process using various tin based catalysts (Sirajuddin et al., 2015).
The objective of this research was to optimize the efficiency of base catalysed transesterification of jojoba oil for biodiesel production using ultrasonic bath in order to vary the operational and process condition such as reaction time and temperature, the molar ratio of alcohol to oil and catalyst concentration.

\section{Materials and Methods}

Feedstock: In the present study, non-edible jojoba-oil was used without purification as a non-edible feed stock for biodiesel production. Jojoba plant is a perennial scrub that has wooden stem, can sustain under extreme climatic conditions. It is the member of Simmondsia chinensis. Jojoba seeds are nut shaped and round, 1-2 cm long, with red brown to dark brown color. The molecular weight of Jojoba oil is $657 \mathrm{~g} \mathrm{~mol}^{-1}$.

Laboratory materials: Ethanol of high grade was used. $\mathrm{CaCO}_{3}$ was used after calcination. $\mathrm{CaCO}_{3}$ was calcined at $900^{\circ} \mathrm{C}$ for $6 \mathrm{hr}$ followed by pulverizing in the porcelain mortar and was cooled to room temperature. In this research, analytical-grade potassium hydroxide and ethanol were used.

Production of Jojoba methyl ester: Crude jojoba oil was preheated to $65^{\circ} \mathrm{C}$, mixed with calculated amount of catalyst and ethanol in a round bottomed flask with reflux assembly and was sonicated for $30 \mathrm{~min}$ at $60{ }^{\circ} \mathrm{C}$ (Shah et al., 2014, Samani et al., 2016). The reaction mixture was cooled to room temperature and allowed to settle for the formation of two layers. The upper oily layer contained biodiesel while the lower alcoholic layer contained glycerol and catalyst. The alcoholic layer was separated by decantation while the oil layer was purified by washing with water, followed by distillation at $60^{\circ} \mathrm{C}$.

Bio diesel analysis: Specific gravity of biodiesel was measured using specific gravity meter ((DA-640 Kyoto Electronics Manufacturing C., Ltd). The $\mathrm{pH}$ of biodiesel was measured with a $\mathrm{pH}$ meter. The caloric value of biodiesel was determined by bomb calorimeter.

Determination of acid value: The acid value could be determined by acid-base titration technique. One gram of sample was dissolved in $10 \mathrm{ml}$ of ethanol, heated for 5-10 min to dissolve the oil in ethanol, and titrated with $0.05 \mathrm{~N}$ potassium hydroxide solution using phenolphthalein as indicator. Acid value was calculated using the following equation:

Acid value $=$ burette reading ${ }^{*}$ mol.wt of $\mathrm{KOH}^{*}$ Normality of $\mathrm{KOH} /$ weight of oil

Determination of iodine value: lodine value was determined by mixing $0.1 \mathrm{~g}$ of biodiesel, $20 \mathrm{ml}$ of carbon tetrachloride and $25 \mathrm{ml}$ of Wijs reagent in a Erlenmeyer flask. The mixture was shaken well and stored in a dark place for $30 \mathrm{~min}$. Then $10 \mathrm{ml}$ of $30 \%$ potassium iodide and $100 \mathrm{ml}$ of distilled water was added to the 
reaction mixture. The contents were titrated against $0.1 \mathrm{~N}$ sodium thiosulphate using starch as indicator. Disappearance of yellow colour was the end point. The same procedure was repeated for the blank solution. The iodine value was be determined by the following formula:

$$
\text { lodine number }=(B-S)^{*} 0.01269 * 100 / \mathrm{W}
$$

where, $B$ and $S$ are the blank and sample values and $W$ is weight of biodiesel.

Determination of saponifacation value: The saponification value was determined by mixing $0.5 \mathrm{~g}$ of biodiesel, $20 \mathrm{ml}$ of $0.5 \mathrm{~N}$ ethanol and $10 \mathrm{ml}$ of $\mathrm{KOH}$ in a round bottom flak. The contents were refluxed followed by heating at $50^{\circ} \mathrm{C}$. The heating was continued till a clear solution appeared and the mixture was cooled. The mixture was titrated against $0.5 \mathrm{~N} \mathrm{HCl}$ using phenolphthalein as an indicator. The same procedure was repeated for the blank solution. The saponification value was determined by the following formula:

$$
\text { Saponification value }=(B-S)^{*} N^{*} 56.1 / \mathrm{W}
$$

where, $B$ and $S$ are the blank and sample values and $W$ is weight of biodiesel.

Determination of cetane number: Cetane number was calculated by the following formula:

\section{Cetane number $=46.354+(5458 / \mathrm{SV})-0.225^{*} \mathrm{IV}$}

where, $\mathrm{SV}$ is the saponification value and IV is the iodine value.

Determination of free fatty acid content: Free fatty acid content was determined by mixing $0.5 \mathrm{~g}$ of biodiesel with $15 \mathrm{ml}$ of ethanol in a Erlenmeyer flask and the mixture was heated near to boiling. The contents were titrated against $0.1 \mathrm{~N} \mathrm{NaOH}$ using phenolphthalein as an indicator.

$$
\text { Free fatty acid }(F F A)=V^{*} N^{*} 28.2 / \mathrm{W}
$$

where, $\mathrm{V}$ and $\mathrm{N}$ refer to the volume and normality of sodium hydroxide.

\section{Results and Discussion}

The parameters investigated for transesterification of jojoba oil were oil-methanol ratio, temperature, reaction time. Various models were followed to optimize the process parameters. As the acid value of jojoba oil was found to 0.2 $\mathrm{mg} \mathrm{KOH} \mathrm{g}^{-1}$, esterification reaction was not performed (Kumar et al., 2017).

The molar ratio of ethanol to oil has a considerable effect on the biodiesel yield. The optimum molar ratio is the decisive parameter in defining the efficiency of the process. In stoichiometry of biodiesel, one mole of oil reacts with 3 mole of ethanol to produce 1 mole of biodiesel and 3 moles of glycerol. As per reaction, stoichiometry 3 moles of methanol was the minimum requirement. Biodiesel yield could be enhanced by increasing methanol amount rather than the stoichiometric requirement. The presence of excess ethanol favours the shift of reaction equilibrium to right-hand side (Kozliak et al., 2013). To study the effect of ethanol to oil ratio, the ratio of 1:1 to 12:1 varied. The $98 \%$ yield could be achieved at 5:1 molar ratio of ethanol to oil and the yield was constant if it exceeded further. However, if the ratio exceeds $5: 1$, the yield decreases due to decrease in catalytic activity with increased methanol content and the glycerol gets dissolved in excess ethanol affecting equilibrium condition (Korkut et al., 2013).

Temperature is the most significant process parameter that needs to be controlled as it determines the kinetics of reaction and affects biodiesel yield. The reaction time varied from $30^{\circ} \mathrm{C}$ to $90^{\circ} \mathrm{C}$ as shown in Fig. 1. The experimental results showed that the reaction rate was slow at low temperature and the yield was $48 \%$ at $50{ }^{\circ} \mathrm{C}$ after 20 min of reaction whereas of $98 \%$ yield could be obtained when the reaction temperature increased to $62{ }^{\circ} \mathrm{C}$. Increase in temperature beyond this temperature resulted in decreased yield due to evaporation of ethanol. The optimum reaction temperature for transesterification of soybean oil to biodiesel was around $62^{\circ} \mathrm{C}$.

Reaction time is one of the most important parameter that affects biodiesel yield. Large amount of biodiesel can be obtained under ultrasonic irradiation. The biodiesel yield of $60 \%$ could be achieved after 30 min and almost complete conversion takes 90 min whereas the same yield could be obtained after $120 \mathrm{~min}$ if the reaction was carried in conventional stirring (Sivasankaran et al., 2016). Ultrasonic irradiation enhances mixing efficiency of the reactants by reducing mass transfer barrier between the reactants resulting in the formation of a fine homogeneous emulsion and increase in the transesterification reaction rate (Khan et al., 2014). If the reaction time was further extended, there was a decrease in the biodiesel yield due to solubility of biodiesel in glycerol. The optimum reaction time was $60 \mathrm{~min}$ for the ultrasonic system.

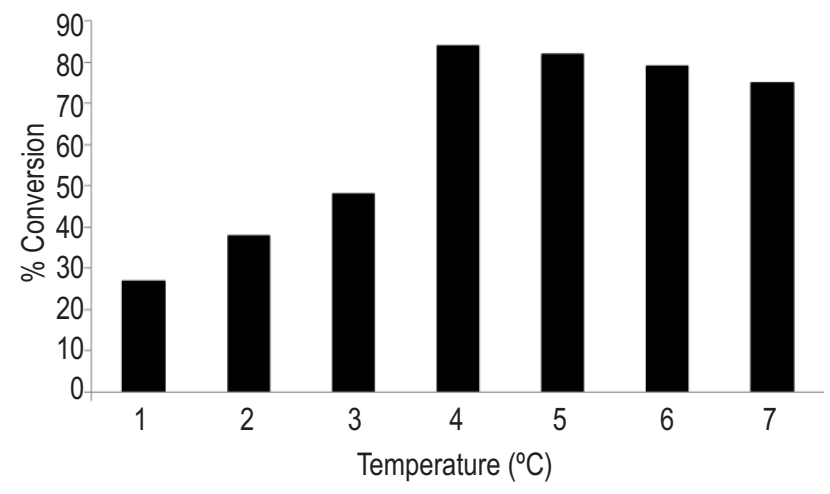

Fig. 1 : Effect of temperature on $\%$ conversion into biodiesel. 
Density is an important physical parameter which greatly affects the engine output power and it was found to be 0.85 which was within the ASTM standard range of fuel. Performance of an engine depends highly on viscosity of bio-diesel which decides drop formation of biodiesel and quality of combustion mixture and its value was found to be $5.25 \mathrm{~mm}^{2} \mathrm{~s}^{-1}$ which was within the range of fuel ASTM standard (Hosseinzadeh-Bandbafha et al., 2014). Pour point is the minimum temperature at which the fuel loses its flow ability and its value was found to be $1{ }^{\circ} \mathrm{C}$. Cloud point is the temperature at which the biodiesel starts forming cloudiness and its value was found to be $10^{\circ} \mathrm{C}$. Both cloud point and pour point refers to minimum operating temperature of biodiesel which can be effectively handled (Hoseini et al., 2019). Caloric value is a crucial factor which indicates the available energy in the fuel and was found to be $37.2 \mathrm{~kJ} \mathrm{~g}^{-1}$. Acid value is used to quantify the acidity of a biodiesel and was found to be $0.6 \mathrm{mg} \mathrm{KOH} \mathrm{g}^{-1}$. Acid value highly depends on the refinement process procedure and solvents used for washing (Hoseini et al., 2018). Saponification value is a measure of the average molecular weight of all fatty acids present and changes according to the pretreatment procedure. The saponification value was found to be $280 \mathrm{mg} \mathrm{KOH} \mathrm{g}^{-1}$.

In conventional stirring method, the time required for biodiesel production was $2.5 \mathrm{hrs}$ with a rotational speed of stirrer at $450 \mathrm{rpm}$ at $50{ }^{\circ} \mathrm{C}$ whereas in the ultra-assisted process, the time requirement was 30 min while the process was carried out at same process parameters of molar ratio, catalyst loading and temperature. Thus, it was observed that ultra-assisted process is most beneficial in terms of time requirement (Ho et al., 2019).

The observed results have proved that ultrasound technology can considerably reduce the reaction time and temperature and increase the yield by reducing the cost and energy contributing a cleaner, safer and green technology for biodiesel production.

\section{References}

Abshishek, C., J. Singh and A. Kumar: Production of biodiesel from soyabean oil biomass as renewable energy resource. J. Environ. Biol., 37, 1303-1307(2016)

Andreo-Martinez, P., N.G. Martinez, M. del M. Duran-del-Amor and J.Q. Medina: Advances on kinetics and thermodynamics of noncatalytic supercritical methanol transesterification of some vegetable oils to biodiesel. Energy Convers. Manag., 173, 187-196 (2018).

Azad, A.K., M.G. Rasul, M.M.K. Khan, S.C. Sharma, M. Mofijur and M.M.K. Bhuiya: Prospects, feedstocks and challenges of biodiesel production from beauty leaf oil and castor oil: A nonedible oil sources in Australia. Renew. Sustain. Energy Rev., 61, 302-318 (2016).

Borugadda, V.B. and V.V. Goud: Biodiesel production from renewable feedstocks: Status and opportunities. Renew. Sustain. Energy Rev., 16, 4763-4784 (2012).

Bouaid, A., L. Bajo, M. Martinez and J. Aracil: Optimization of biodiesel production from jojoba oil. Process Saf. Environ. Prot., 85,
378-382 (2007).

Canoira, L., R. Alcantara, M.J. Garcia-Martinez and J. Carrasco: Biodiesel from Jojoba oil-wax: Transesterification with methanol and properties as a fuel. Biom. Bioen., 30, 76-81 (2006).

Chen, G., R. Shan, J. Shi and B. Yan: Ultrasonic-assisted production of biodiesel from transesterification of palm oil over ostrich eggshellderived CaO catalysts. Biores. Technol., 171, 428-432 (2014).

Dubey, P. and R. Gupta: Effects of dual bio-fuel (Jatropha biodiesel and turpentine oil) on a single cylinder naturally aspirated diesel engine withoutEGR. Appl. Therm. Eng., 115, 1137-1147(2017).

Dubey, P. and R. Gupta: Influences of dual bio-fuel (Jatropha biodiesel and turpentine oil) on single cylinder variable compression ratio diesel engine. Renew. Ener., 115, 1294-1302 (2018)

El-Boulifi, N., M. Sanchez, M. Martínez and J. Aracil: Fatty acid alkyl esters and monounsaturated alcohols production from jojoba oil using short-chain alcohols for biorefinery concepts. Ind. Crops Prod., 69, 244-250 (2015).

Gülüm, M and A. Bilgin: Regression models for predicting some important fuel properties of corn and hazelnut oil biodiesel-diesel fuel blends. Exergetic. Energy. Environ. Dimens., 829-850 (2017).

Ho, W.W.S., H.K. Ng and S. Gan: Advances in ultrasound-assisted transesterification for biodiesel production. Appl. Therm. Eng., 100, 553-563 (2016).

Hoseini, S.S., G. Najafi, B. Ghobadian, R. Mamat, M.T. Ebadi and T. Yusaf: Characterization of biodiesel production (ultrasonicassisted) from evening-primroses (Oenothera lamarckiana) as novel feedstock and its effect on $\mathrm{Cl}$ engine parameters. Renew. Energy, 130, 50-60 (2019).

Hoseini, S.S., G. Najafi, B. Ghobadian, R. Mamat, M.T. Ebadi and T. Yusaf. Ailanthus altissima (tree of heaven) seed oil: Characterisation and optimisation of ultrasonication-assisted biodiesel production. Fuel, 220, 621-630 (2018).

Hosseinzadeh-Bandbafha, H., M. Tabatabaei, M. Aghbashlo, M. Khanali and A. Demirbas: A comprehensive review on the environmental impacts of diesel/biodiesel additives. Energy Convers. Manag., 174, 579-614 (2018).

Khan, T.M.Y., A.E. Atabani, I.A. Badruddin, A. Badarudin, M.S. Khayoon and S. Triwahyono: Recent scenario and technologies to utilize non-edible oils for biodiesel production. Renew. Sustain. Energy Rev., 37, 840-851 (2014).

Korkut, I. and M. Bayramoglu: Selection of catalyst and reaction conditions for ultrasound assisted biodiesel production from canola oil. Renew. Energy., 116, 543-551 (2018).

Kozliak, E., R. Mota, D. Rodriguez, P. Overby, A. Kubatova, D. Stahl, V. Niri, G. Ogden and W. Seames: Non-catalytic cracking of jojoba oil to produce fuel and chemical by-products. Ind. Crops Prod., 43, 386-392 (2013).

Kumar, G., V. Singh and D. Kumar: Ultrasonic-assisted continuous methanolysis of Jatropha curcas oil in the appearance of biodiesel used as an intermediate solvent. Ultrason. Sonochem., 39, 384-391 (2017).

Kumar, S., R. Kumar and M. Kumar: Experimental investigations of oxidation stability of biodiesel produced from Prunus armeniaca oil (apricot oil) and effect of various antioxidants on stability, engine performance and emissions. Fuel, 216, 861-869 (2018).

Marinkovic, D.M., M.V. Stankovic, A.V. Velickovic, J.M. Avramovic, M.R. Miladinovic, O.O. Stamenkovic, V.B. Veljkovic and D.M. Jovanovic: Calcium oxide as a promising heterogeneous catalyst for biodiesel production: Current state and perspectives. Renew. 
Sustain. Energy Rev., 56, 1387-1408 (2016).

Mostafaei, M., B. Ghobadian and M. Banakar: Optimization of ultrasonic assisted continuous production of biodiesel using response surface methodology. Ultrason. Sonochem., 27, 54-61 (2015).

Navas, M.B., I.D. Lick, P.A. Bolla, M.L. Casella and J.F. Ruggera: Transesterification of soybean and castor oil with methanol and butanol using heterogeneous basic catalysts to obtain biodiesel. Chem. Eng. Sci., 187, 444-454 (2018).

Qiu, F., Y. Li, D. Yang, X. Li and P. Sun: Biodiesel production from mixed soybean oil and rapeseed oil. Appl. Energy, 88, 2050-2055 (2011).

Rajak, U. and T.N. Verma: Effect of emission from ethylic biodiesel of edible and non-edible vegetable oil, animal fats, waste oil and alcohol in $\mathrm{Cl}$ engine. Energy Convers. Manag., 166, 704-718 (2018).

Sanchez-Cantu, M., M.M. Tellez, L.M. Perez-Díaz, R.Z. Diaz, J.C. Hilario-Martinez and J.S. Ramirez: Biodiesel production under mild reaction conditions assisted by high shear mixing. Renew. Energy, 130,174-181 (2019).

Sánchez, M., M.R. Avhad, J.M. Marchetti, M. Martinez and J. Aracil: Enhancement of the jojobyl alcohols and biodiesel using a renewable catalyst in a pressurized reactor. Energy Convers. Manag., 126, 1047-105(2016).

Sanchez, M., M.R. Avhad, J.M. Marchetti, M. Martinez and J. Aracil: Jojoba oil: A state of the art review and future prospects. Energy Convers. Manag., 129, 293-304 (2016).

Sanchez, M., J.M. Marchetti, N. El Boulifi, J. Aracil and M. Martínez: Kinetics of Jojoba oil methanolysis using a waste from fish industry as catalyst. Chem. Eng. J., 262, 640-647 (2015).

Shah, M., M. Tariq, S. Ali, Q.X. Guo and Y. Fu: Transesterification of jojoba oil, sunflower oil, neem oil, rocket seed oil and linseed oil by tin catalysts. Biomass and Bioenergy, 70, 225-229 (2014).

Shah, M., S. Ali, M. Tariq, N. Khalid, F. Ahmad and M.A. Khan: Catalytic conversion of jojoba oil into biodiesel by organotin catalysts, spectroscopic and chromatographic characterization. Fuel, 118, 392-397 (2014).

Samani, B.H., H. Zareiforoush, Z. Lorigooini, B. Ghobadian, S. Rostami and E. Fayyazi: Ultrasonic-assisted production of biodiesel from Pistacia atlantica Desf. oil. Fuel., 168, 22-26 (2016).

Sandouqa, A. and Z. Al-Hamamre: Energy analysis of biodiesel production from jojoba seed oil. Renew. Energy, 130, 831-842 (2019).

Sirajuddin, M., M. Tariq and S. Ali: Organotin(IV) carboxylates as an effective catalyst for the conversion of corn oil into biodiesel. J. Organomet. Chem., 779, 30-38 (2015).

Sivaramakrishnan, R. and A. Incharoensakdi: Microalgae as feedstock for biodiesel production under ultrasound treatment - A review. Bioresour. Technol., 250, 877-887 (2018).

Sivasankaran, C., P.K. Ramanujam and S. Shanmugam: Purification and characterization of waste stream glycerol derived from biodiesel industry. J. Environ. Biol., 37, 1529-1534 (2016).

Talebian-Kiakalaieh, A., N.A.S. Amin and H. Mazaheri. A review on novel processes of biodiesel production from waste cooking oil. Appl. Energy, $104,683-710$ (2013)

Verma, P., M.P. Sharma and G. Dwivedi: Impact of alcohol on biodiesel production and properties. Renew. Sustain. Energy Rev., 56, 319-333 (2016).

Yadav, M. and Y.C. Sharma: Process optimization and catalyst poisoning study of biodiesel production from kusum oil using potassium aluminum oxide as efficient and reusable heterogeneous catalyst. J. Clean. Prod., 199, 593-602 (2018).

Yang, L., M. Takase, M. Zhang, T. Zhao and X. Wu: Potential non-edible oil feedstock for biodiesel production in Africa: Survey. Renew. Sustain. Energy Rev., 38, 461-477 (2014).

Yan, Y., X. Li, G. Wang, X. Gui, G. Li, F. Su, X. Wang and T. Liu: Biotechnological preparation of biodiesel and its high-valued derivatives:A review. Appl. Energy, 113, 1614-1631 (2014). 